\title{
LETTERS
}

\section{Successful treatment of severe rheumatoid vasculitis by infliximab}

\author{
L Unger, M Kayser, H G Nüsslein
}

Ann Rheum Dis 2003;62:587-588

$\mathrm{R}$ heumatoid vasculitis (RV) is a severe complication of rheumatoid arthritis (RA), which like a primary necrotising vasculitis can affect any organ but characteristically presents with painful cutaneous ulcers and systemic inflammation. ${ }^{12}$ Usually patients with refractory RA are affected who, therefore, had already undergone extensive immunosuppressive treatment. The prognosis is poor and most patients die from infectious complications, cardiac failure, or cerebral insult. ${ }^{3-6}$ Cyclophosphamide (CYC) is the preferred treatment but is often not well tolerated and does not contain the synovitis. ${ }^{3}$ We report the cases of three patients with RV who could not sufficiently be treated by CYC and steroids but responded very well to infliximab infusion therapy.

\section{CASE REPORTS}

\section{Case 1}

A 48 year old male patient with longlasting RA was admitted because of general malaise, dyspnoea, oedema, pleural and pericardial effusions, increased creatinine and liver enzymes, leucocytopenia, thrombocytopenia, decreased $\mathrm{C} 4$ and $\mathrm{CH}_{50}$, and increased levels of circulating immune complexes. The diagnosis of RV was established. The patient's condition did not sufficiently improve after treatment with steroid pulses, high dose CYC, or even plasmapheresis. He developed a life threatening heart failure caused by a "swinging heart" due to the pericardial effusion, which required immediate and repeated drainage (fig 1). As a last resort we decided to start

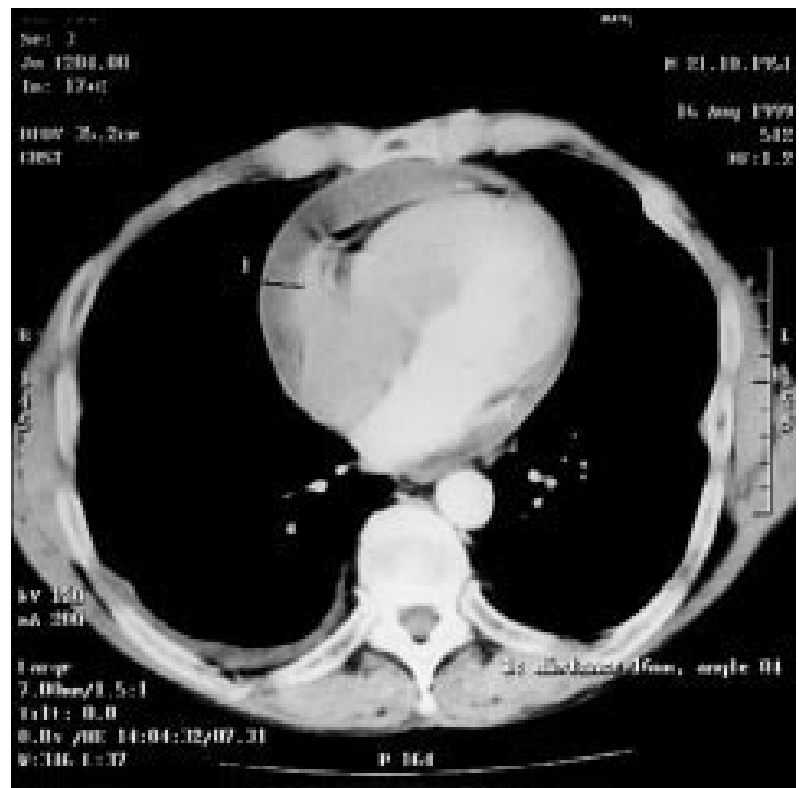

Figure 1 Case 1: chest computed tomographic scan showing the pericardial effusion due to RV. infliximab treatment at $3 \mathrm{mg} / \mathrm{kg}$. After the first infusion his condition improved rapidly and the pericardial effusion, in particular, disappeared within two weeks. All laboratory findings returned to normal. He continues to receive infliximab every eight weeks and is in good clinical condition. Even the activity of his RA, previously not sufficiently controlled by methotrexate alone, has decreased significantly.

\section{Case 2}

A 60 year old woman with a history of aggressive seropositive RA for 36 years suddenly developed painful ulcers on her left leg. The diagnosis of RV was established by biopsy from the ulcer rim. CYC bolus therapy was started and steroids also had to be increased. She responded partially to CYC, but the ulcers did not heal completely. Because of infections and leucopenia the dose and interval of the infusions often had to be adjusted. After 17 boli within 22 months the CYC therapy was stopped because of severe leucopenia. The lesions worsened after an ineffective trial of cyclosporin A ( fig 2A). Infliximab was given at $3 \mathrm{mg} / \mathrm{kg}$ in weeks 0,2 , and 6 and thereafter every eight
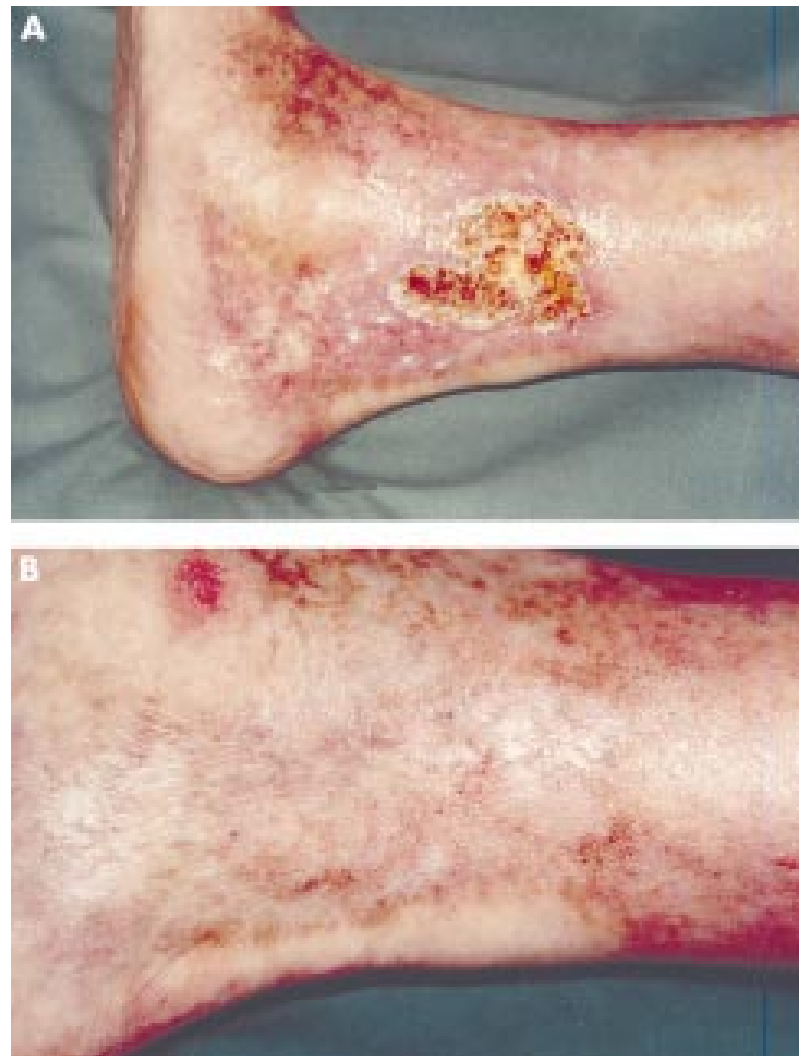

Figure 2 Case 2: leg ulcer before infliximab treatment was started (A) and the same lesion after seven infliximab infusions (B). 
weeks. The ulcers improved soon after the second infusion and were completely healed after nine months (fig 2B). Her RA activity also improved greatly.

\section{Case 3}

A 64 year old male patient with RA was admitted to our hospital with a fistula between the colon and the urine bladder, which required immediate surgery because of imminent perforation. After surgery the wound did not heal. In addition, painful ulcers appeared on both legs, the scrotum, and other skin areas. All biopsies including that from the fistula, revealed necrotising vasculitis. CYC bolus therapy was started. The scrotal ulcer healed and the belly wound gradually improved, but the leg ulcers remained unchanged and his RA activity increased sharply. CYC had to be stopped because of leucopenia. Infliximab was started at $3 \mathrm{mg} / \mathrm{kg}$ at weeks 0,2 , and 6 , and thereafter every eight weeks. The treatment was immediately effective for his synovitis and after a while the belly wound and the leg ulcers healed also.

\section{CONCLUSION}

These cases demonstrate a very rapid and sustained improvement not only of the vasculitic symptoms but also of the inflammatory joint activity, suggesting that infliximab may be a valuable alternative to standard CYC/steroid therapy for severe RV.

\section{Authors' affiliations}

L Unger, M Kayser, H G Nüsslein , I Medizinische Klinik, Krankenhaus Dresden-Friedrichstadt, Dresden, Germany

Correspondence to: Professor H G Nüsslein, I Medizinische Klinik, Krankenhaus Dresden-Friedrichstadt, Friedrichstr 41, 01067 Dresden, Germany; nuesslein-hu@khdf.de

Accepted 5 December 2002

\section{REFERENCES}

1 McRorie ER, Ruckley CV, Nuki G. The relevance of large-vessel vascular disease and restricted ankle movement to the aetiology of leg ulceration in rheumatoid arthritis. Br J Rheumatol 1998;37:1295-8.

2 Pun YLW, Barraclough DRE, Muirden KD. Leg ulcers in rheumatoid arthritis. Med J Aust 1990;158:585-7.

3 Scott DGI, Bacon PA. Intravenous cyclophosphamide plus methylprednisolone in treatment of systemic rheumatoid vasculitis. Am J Med 1984;76:377-83

4 Turesson C, Jacobson L, Bergstrom U. Extra-articular rheumatoid arthritis: prevalence and mortality. Rheumatology (Oxford) 1999;38:66874

5 Voskuyl AE, Zwinderman AH, Westedt ML, Vandenbroucke JP, Breedveld FC, Hazes JM. The mortality of rheumatoid vasculitis compared with rheumatoid arthritis. Arthritis Rheum 1996;39:266-71.

6 McRorie ER, Jobanputra P, Ruckley CV, Nuki G. Leg ulceration in rheumatoid arthritis. Br J Rheumatol 1994;33:1078-84.

\title{
Low dose methotrexate osteopathy in a patient with polyarticular juvenile idiopathic arthritis
}

\author{
M Rudler, J Pouchot, F Paycha, S Gentelle, A Grasland, P Vinceneux
}

 ow dose methotrexate (MTX) is widely used in the treatment of rheumatoid arthritis (RA) and various rheumatic -disorders, including juvenile idiopathic arthritis (JIA). MTX is a folate antagonist, and its main adverse effects, which include haematological and hepatic toxicities, are well known. Used in high dosages in paediatric oncology, MTX has been associated with an osteopathy which is characterised by bone pain, osteoporosis, and insufficiency fractures of the legs. ${ }^{1}$ The occurrence of MTX osteopathy in patients treated with low dose MTX has been reported but is still debated. ${ }^{2-4}$

\section{CASE REPORT}

A 36 year old woman presented with severe polyarthralgias lasting for the past two months. She had a 27 year history of polyarticular type JIA, and had received prednisone up to 10 $\mathrm{mg} /$ day for the past 25 years. She had no history of osteoporotic or insufficiency fractures. Physical examination showed multiple synovitis of hands, wrists, knees, and ankles. Laboratory investigations showed a slight increase of $\mathrm{C}$ reactive protein of $20 \mathrm{mg} / \mathrm{l}$, and a strongly positive rheumatoid factor. Low dose oral MTX was started at an initial weekly dose of $7.5 \mathrm{mg}$ (weight $56 \mathrm{~kg}$, height $156 \mathrm{~cm}$, albumin $42 \mathrm{~g} / \mathrm{l}$, serum creatinine $60 \mu \mathrm{mol} / \mathrm{l})$.

In the absence of significant improvement, two months later, the weekly dose of MTX was increased to $10 \mathrm{mg}$. One month later, while she had a persistent active polyarthritis, and after having received a cumulative dose of $97.5 \mathrm{mg}$ of MTX, she complained of sudden and spontaneous onset of right groin pain that was relieved by rest. Standard radiographs showed a fracture of both inferior and superior right pubic ramus. Serum calcium and 25hydroxycholecalciferol levels were normal. Pain resolved with rest in a few weeks. Treatment with MTX was maintained.

Two months later, the patient presented with bilateral leg pain increased by weight bearing and relieved by rest. At that time, the received cumulative dose of MTX was $137.5 \mathrm{mg}$. Standard radiographs were normal but bone scanning with technetium-99m disclosed multiple areas of increased uptake (superior and inferior right pubic ramus, pubic symphysis, left hip, bilateral femoral condyles, right calcaneum) characteristic of multiple new insufficiency fractures (fig 1). MTX osteopathy was suspected and the treatment was discontinued.

\section{DISCUSSION}

MTX osteopathy was initially reported in children with acute leukaemia treated with a high dose of MTX. ${ }^{1}$ Patients present with severe leg pain, osteopenia, and insufficiency fractures. Several reports have also suggested that the occurrence of spontaneous insufficiency fractures is more common than expected in patients with inflammatory rheumatism treated with low dose MTX. ${ }^{3-6}$ The effect of MTX on bone mineral density has been rarely studied. In patients with RA, low dose MTX treatment was not associated with increased bone loss in the lumbar spine or the femoral neck at three years. ${ }^{7}$ However, among the patients who were also receiving prednisone $(\geqslant 5 \mathrm{mg} /$ day), MTX use was associated with greater bone loss 


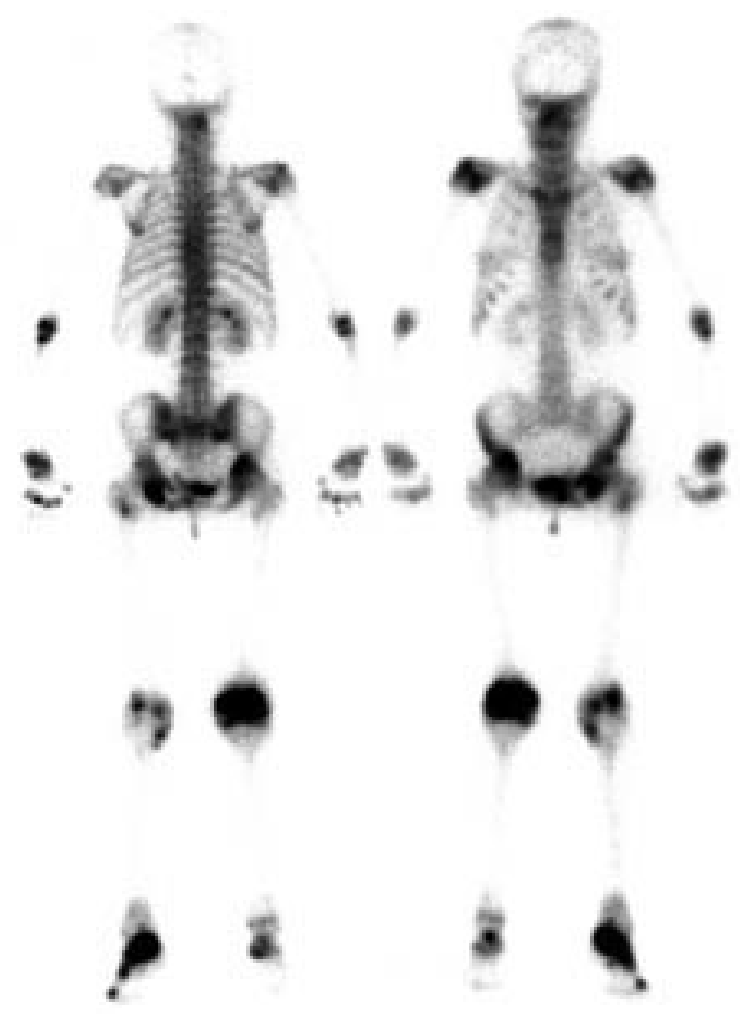

Figure 1 Technetium- $99 \mathrm{~m}$ bone scan (anterior and posterior views, late images) showing multiple zones of enhanced uptake in the superior and inferior right pubic ramus, pubic symphysis, left hip, bilateral femoral condyles, and right calcaneum.

in the lumbar spine, suggesting that the addition of MTX to prednisone may cause more bone loss than would be expected from corticosteroid treatment alone. ${ }^{7}$ Recently, Uehara et al have shown in vitro that MTX impairs bone formation by inhibiting the differentiation of osteoblast precursors. $^{8}$
In patients with inflammatory arthritis receiving corticosteroids, MTX treatment should be considered as an additional risk factor for stress fractures. As far as we know this is the first reported case of MTX osteopathy in a patient with JIA. Rheumatologists should be aware of this complication as it may be easily confused with synovitis. Involvement of the leg articular or periarticular area should raise diagnostic clinical awareness. A bone scan is particularly useful for the diagnosis. $^{3}$

\section{Authors' affiliations}

M Rudler, J Pouchot, S Gentelle, A Grasland, P Vinceneux, Service de Médecine Interne, Hôpital Lovis Mourier, Faculté Xavier Bichat, Paris VII, France

F Paycha, Service de Médecine Nucléaire, Hôpital Louis Mourier, Faculté Xavier Bichat, Paris VII, France

Correspondence to: Dr J Pouchot, Service de Médecine Interne, Hôpital Louis Mourier 178, rue des Renouillers, 92700 Colombes, France; Jacques.pouchot@lmr.ap-hop-paris.fr

Accepted 26 November 2002

\section{REFERENCES}

1 Ragab AH, Frech RS, Vietti TJ. Osteoporotic fractures secondary to methotrexate therapy of acute leukaemia in remission. Cancer 1970;25:580-5

2 Maenaut K, Westhovens R, Dequeker J. Methotrexate osteopathy, does it exist? J Rheumatol 1996;23:2156-9.

3 Stevens H, Jacobs JWG, Van Riik PP, De Klerk JMH. Methotrexate osteopathy demonstrated by technetium-99m HDP bone scintigraphy. Clin Nucl Med 2001;26:389-91.

4 Wijnands $M$, Burgers. Stress fracture in long term methotrexate treatment for psoriatic arthritis. Ann Rheum Dis 2001;60:736-8.

5 Bologna C, Sany J, Jorgensen C. Possible role of methotrexate in the distal tibia fractures in a patient with rheumatoid arthritis. Clin Exp Rheumatol 1996;14:343-4

6 Zonneveld IM, Bakker WK, Dijkstra PF, Bos JD, van Soesbergen RM, Dinant HJ. Methotrexate osteopathy in long-term low-dose methotrexate treatment for psoriasis and rheumatoid arthritis. Arch Dermatol 1996:132:184-7.

7 Buckley LM, Leib ES, Cartularo KS, Vacek PM, Cooper SM. Effects of low dose methotrexate on the bone mineral density of patients with rheumatoid arthritis. J Rheumatol 1997;24:1489-94.

8 Uehara R, Suzuki Y, Ichikawa Y. Methotrexate (MTX) inhibits osteoblastic differenciation in vitro: possible mechanism of MTX osteopathy. J Rheumatol $2001 ; 28: 251-6$.

\section{More on anticardiolipin and anti- $\beta_{2}$ glycoprotein I in systemic sclerosis}

\section{M Antonioli, E Danieli, P Airò, R Cattaneo, A Tincani}

$\mathrm{P}$ atients with systemic sclerosis (SSc) may have arterial and venous thrombosis and, according to the limited and controversial data available, may have an increased incidence of pregnancy losses. ${ }^{1}$ These observations preceded the definition of antiphospholipid syndrome (APS) as the association of thrombosis and pregnancy loss with antiphospholipid antibodies (aPL), and did not focus on patients with SSc. However, the association of thrombosis and aPL, detected as lupus anticoagulant (LAC) and/or anticardiolipin antibodies (aCL), although rare, was described in SSc, ${ }^{2}$ supporting the possible existence of a "secondary" APS in SSc. $^{3}$

In view of the fact that most aCL are directed to $\beta$, glycoprotein I (a $\beta_{2}$ GPI $),{ }^{4}$ the possibility that patients with APS may be negative for aCL, but positive for $a \beta_{2} \mathrm{GPI},{ }^{5}$ and considering the scarcity of data examining this issue in SSc, we read with great interest the recent study by Schoenroth et al, ${ }^{6}$ who examined the frequency of a $\beta_{2}$ GPI in SSc. The authors found $\operatorname{IgM~a} \beta_{2}$ GPI in $2 / 26(8 \%)$ patients and IgG in none. This finding did not seem to be related to any clinical or laboratory features. In another report, 80 patients with SSc were studied using an enzyme linked immunosorbent assay (ELISA) detecting the complex cardiolipin/ $\beta_{2}$ GPI. A similar prevalence of $\mathrm{aCL} / \beta_{2}$ GPI ( $10 \% \operatorname{IgG}$ and $\left.6 \% \operatorname{IgM}\right)$, was found and a significant correlation between the presence of $\mathrm{aCL} / \beta_{2}$ GPI IgG and isolated pulmonary hypertension.

Looking retrospectively at our cohort of 115 patients with SSc fulfilling the American College of Rheumatology criteria, 
Table 1 Clinical and laboratory features of 18 patients with $\mathrm{SSc} a C L+$ and/or a $\beta_{2} \mathrm{GPI}+$

\begin{tabular}{|c|c|c|c|c|c|c|c|c|}
\hline \multirow{2}{*}{$\begin{array}{l}\text { Sex, age, } \\
\text { subset of } \\
\text { SSc }\end{array}$} & \multicolumn{2}{|c|}{$\mathrm{a} \beta_{2} \mathrm{GPI}^{*}$} & \multicolumn{2}{|l|}{$a C L^{*}$} & \multirow[b]{2}{*}{ Thromboses } & \multirow[b]{2}{*}{ Pregnancy loss } & \multirow[b]{2}{*}{$\begin{array}{l}\text { Other clinical and } \\
\text { laboratory features }\end{array}$} & \multirow[b]{2}{*}{$\begin{array}{l}\text { Antithrombotic } \\
\text { treatment }\end{array}$} \\
\hline & $\begin{array}{l}\lg G \\
\text { (OD) }\end{array}$ & $\begin{array}{l}\lg M \\
\text { (OD) }\end{array}$ & $\begin{array}{l}\operatorname{lgG} \\
\text { (GPL) }\end{array}$ & $\begin{array}{l}\lg M \\
\text { (MPL) }\end{array}$ & & & & \\
\hline$F, 37, I$ & 1.68 & 0.36 & 67 & 35 & No & No & Overlap SLE, LAC- & Aspirin \\
\hline$F, 55, d$ & 0.38 & Neg & Neg & $\mathrm{Neg}$ & No & No & & Aspirin \\
\hline $\mathrm{F}, 57, \mathrm{I}$ & Neg & 2.11 & Neg & $\mathrm{Neg}$ & DVT & 2 Miscarriages & Livedo reticularis, LAC- & Warfarin \\
\hline $\mathrm{F}, 61, \mathrm{I}$ & $\mathrm{Neg}$ & 0.84 & Neg & $\mathrm{Neg}$ & No & No & PBC, LAC- & Aspirin \\
\hline$F, 54, I$ & Neg & 0.66 & Neg & Neg & No & $\begin{array}{l}1 \text { Miscarriage, } 1 \text { intrauterine } \\
\text { death }\end{array}$ & & Aspirin \\
\hline$F, 64, I$ & Neg & 0.58 & Neg & Neg & No & No & LAC- & Aspirin \\
\hline$M, 65,1$ & Neg & 0.53 & 13 & $\mathrm{Neg}$ & Subclavian artery & & Non-erosive arthritis, LAC- & Ticlopidine \\
\hline $\mathrm{F}, 76, \mathrm{I}$ & Neg & 0.43 & $\mathrm{Neg}$ & 15 & Recurrent DVT in leg & No & & Aspirin \\
\hline$F, 59, \mathrm{I}$ & Neg & 0.42 & Neg & 15 & No & No & Pulmonary hypertension & $\begin{array}{l}\text { Warfarin + } \\
\text { iloprost }\end{array}$ \\
\hline$F, 63, I$ & Neg & 0.38 & Neg & Neg & No & No & Superficial phlebitis & Aspirin \\
\hline $\mathrm{F}, 78, \mathrm{l}$ & Neg & 0.35 & Neg & Neg & No & No & & Aspirin \\
\hline $\mathrm{F}, 43, \mathrm{I}$ & Neg & 0.32 & $\mathrm{Neg}$ & $\mathrm{Neg}$ & No & No & & Aspirin \\
\hline$F, 59, I$ & Neg & 0.31 & Neg & Neg & No & No & Overlap PM/SLE, LAC- & Aspirin \\
\hline$F, 60, I$ & Neg & 0.30 & $\mathrm{Neg}$ & Neg & No & No & & No \\
\hline$F, 65, I$ & $\mathrm{Neg}$ & $\mathrm{Neg}$ & 30 & $\mathrm{Neg}$ & Myocardial infarction & No & $\begin{array}{l}\text { Pulmonary hypertension, } \\
\text { encephalopathy, LAC+ }\end{array}$ & $\begin{array}{l}\text { Warfarin + } \\
\text { iloprost }\end{array}$ \\
\hline$F, 37, d$ & Neg & Neg & 18 & Neg & Saphenous vein thrombosis & No & Overlap SLE & Aspirin \\
\hline $\mathrm{F}, 54, \mathrm{I}$ & Neg & Neg & 20 & $\mathrm{Neg}$ & No & No & & Aspirin \\
\hline $\mathrm{F}, 52, \mathrm{~d}$ & Neg & $\mathrm{Neg}$ & Neg & 10.7 & No & No & & Aspirin \\
\hline
\end{tabular}

${ }^{*}$ Normal values: $a \beta_{2} G P I \lg G<0.13, \lg M<0.28 ; a C L \lg G<10, \lg M<10$.

SLE, systemic lupus erythematosus; LAC, lupus anticoagulant; DVT, deep vein thrombosis; PBC, primary biliary cirrhosis; PM, polymyositis.

we found that, where clinically indicated, both aCL and a $\beta_{2}$ GPI had been routinely evaluated in 60 patients (four male, 56 female; mean age 57 years; mean disease duration 13 years, range 1-42). These patients were classified, according to Le Roy (1988), as having limited (lSSc; $n=48$ ) or diffuse SSc (dSSc; $n=12)$. Twenty seven patients were anticentromere positive and 16 anti-Scl-70+. Anticardiolipin antibodies were evaluated by a routine standardised method, ${ }^{8}$ and $a \beta_{2}$ GPI as described by Balestrieri et al'; values higher than the 99th centile of 100 healthy blood donors were regarded as positive.

Positive tests for aCL were found in 8/60 (13\%) patients and for $a \beta_{2}$ GPI in $14 / 60(23 \%)$ (table 1 ). The prevalence of a $\beta_{2}$ GPI was higher than in previous studies, probably because we performed the test only where clinically indicated; therefore, the prevalence in patients with SSc overall may differ.

Among 60 patients, eight had a history of documented venous (four) or arterial (four) thromboses: two were aCL+ $\mathrm{a} \beta_{2}$ GPI+, two aCL $+\mathrm{a} \beta_{2}$ GPI-, one aCL- $\mathrm{a} \beta_{2}$ GPI + , and three aCL- $a \beta_{2}$ GPI-; $a C L$ and anamnestic thrombosis were significantly related $\left(\mathrm{p}<0.01 ; \chi^{2}\right.$ with Yates's correction $)$. Two patients had "primary" (that is, not secondary to lung fibrosis) pulmonary hypertension. One patient was aCL $+a \beta_{2}$ GPI + whereas the other one was aCL + and $\mathrm{LAC}+$, but a $\beta_{2} \mathrm{GPI}-;$ aCL and pulmonary hypertension were significantly related $(p=0.02)$. According to the Sapporo criteria ${ }^{10}$ three patients had a significant history of pregnancy loss without thromboses: one was aCL- a $\beta_{2}$ GPI + , but two were aCL- $a \beta_{2}$ GPI-.

In our experience, the presence of aCL in patients with SSc was significantly associated with a history of thrombosis and with pulmonary hypertension. Anti- $\beta_{2}$ GPI seemed to be less specific, but allowed the identification of a woman with deep vein thrombosis, two miscarriages, and livedo reticularis. Although these events can be related to other thrombophilic conditions, none of these conditions was found in this patient. The association with $a \beta_{2}$ GPI suggests that she might be defined as having "aCL-, a $\beta_{2}$ GPI + APS" or "equivocal APS".
In conclusion, in patients with SSC and APS related symptoms, the evaluation of a $\beta_{2}$ GPI can help to define the clinical picture and the specific treatment required.

\section{Authors' affiliations}

C M Antonioli, E Danieli, P Airò, R Cattaneo, A Tincani , Servizio di Reumatologia ed Immunologia Clinica, Spedali Civili, Brescia, Italy

Correspondence to: Dr P Airò, Servizio di Immunologia Clinica, Spedali Civili, 25123 Brescia, Italy; cattaneo@master.cci.unibs.it

Accepted 22 November 2002

\section{REFERENCES}

1 Black CM. Stevens WM. Pregnancy in patients with rheumatic diseases. Scleroderma. Rheum Dis Clin North Am 1989;15:193-212.

2 Kane D, McSweeney F, Swan N, Bresnihan B. Catastrophic antiphospholipid syndrome in primary systemic sclerosis. J Rheumatol 1998:25:810-12.

3 Cervera R, Piette JC, Font J, Khamashta MA, Shoenfeld Y, Camps MT, et al. Antiphospholipid syndrome: clinical and immunologic manifestations and patterns of disease expression in a cohort of 1,000 patients. Arthritis Rheum 2002;46:1019-27.

4 Tincani A, Balestrieri G, Spatola L, Cinquini M, Meroni PL, Roubey RAS. Anticardiolipin and anti- $\beta_{2}$ glycoprotein I in the diagnosis of antiphospholipid syndrome. Clin Exp Rheumatol 1998;16:396-402.

5 Harris EN, Pierangeli SS. 'Equivocal' antiphospholipid syndrome. J Autoimmun 2000;15:81-5.

6 Schoenroth L, Fritzler M, Lonzetti L, Senecal JL. Antibodies to $\beta$ glycoprotein I and cardiolipin in SSc. Ann Rheum Dis 2002;61:183-4.

7 Ihn H, Sato S, Fujimoto M, Kikuchi K, Igarashi A, Soma Y, et al. Measurement of anticardiolipin antibodies by ELISA using $\beta_{2}$-glycoprotein I $\left(\beta_{2}-\right.$ GPI) in systemic sclerosis. Clin Exp Immunol 1996; 105:475-9.

8 Harris $\mathbf{E}$. The second international anticardiolipin standardization workshops. The Kingston Anti-Phospholipid Antibody Study (KAPS) Group. Am J Clin Pathol 1990;94:476-84

9 Balestrieri G, Tincani A, Spatola L, Allegri F, Prati E, Cattaneo R, et al Anti- $\beta_{2}$ glycoprotein I: a marker of antiphospholipid syndrome? Lupus 1995:4:122-30.

10 Wilson W, Gharavi A, Koike T, Lockshin MD, Branch DW, Piette JC, et al International consensus statement on preliminary classification criteria for definite antiphospholipid syndrome: report of an international workshop. Arthritis Rheum 1999:42:1309-11. 